\title{
Auf den Hund gekommen
}

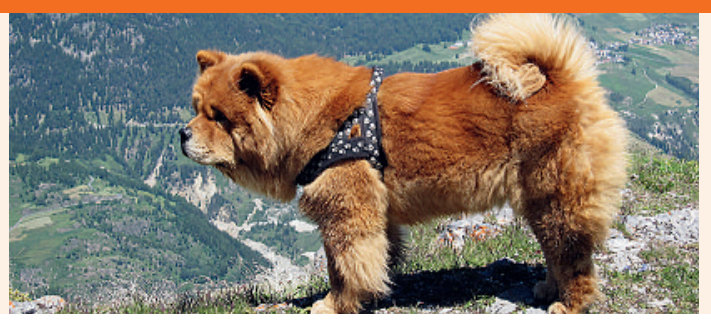

Daniel Schlossberg

Korrespondenz:

Dr. med. Daniel Schlossberg

Bachmattstrasse 53

CH-8048 Zürich

daniel.schlossberg@hin.ch
Glücklich Verheiratete leben länger, besagen viele Studien. Lassen wir dies so im Raum stehen und wenden wir uns dem Hund zu.

In einer australischen Studie, die Anderson, Reid und Jennings 1992 veröffentlichten, wurde belegt, dass Tierbesitzer geringere gesundheitliche Risikofaktoren wie erhöhte Blutfettwerte und erhöhten Blutdruck aufweisen und seltener an einem Herz-Kreislauf-Leiden erkranken. Dies ist in erster Linie auf die regelmässige, körperliche Bewegung zurückzuführen. Bei Menschen, die zu häufigen Stimmungsschwankungen oder zu Depressionen neigen, können Tiere sogar therapeutische Hilfe leisten. Der Psychologe Prof. Reinhold Bergler von der Universität Bonn fand heraus, dass Hundebesitzer Probleme und Schicksalsschläge besser in den Griff bekommen als andere Menschen.

Die medizinische Forschung belegt, dass Hundehalter statistisch länger leben. Die Sprachforschung legt nahe, dass «wer auf den Hund gekommen ist», mit der Doppelbödigkeit des Ausdrucks lebt. Mindestens 14000 Jahre schon leben Menschen mit Hunden zusammen, auch das ist mehr oder weniger gut belegt.

Wir alle kennen die, die auf den Hund gekommen sind, und meinen damit Menschen, die «heruntergekommen» sind, die müde, krank, verwahrlost oder auch wirtschaftlich am Ende sind.

Auf den Hund gekommen bin ich auch. Es begann alles mit einer Beziehung, die man heute im Raritätenkabinett in der Kategorie «glücklich verheiratet» noch findet. Ich hatte Angst vor Hunden und so habe ich meine erste Hundebekanntschaft, einen Springer Spaniel, mit einem Adventskalender bestochen. Das hat funktioniert. Inzwischen ist viel geschehen.

Auf den Hund gekommen bin ich erneut, als wir vor der Frage standen, unseren verstorbenen Hund durch einen neuen nicht zu ersetzen, nicht vergessen $\mathrm{zu}$ machen, aber durch einen neuen jungen Hund erst so richtig zu verabschieden. Im ersten hundefreien Monat seit 14 Jahren realisierten wir, dass unsere Bäuche rasch anschwollen, wir den obligaten Abendspaziergang nach getaner Arbeit vermisst haben und wir auf Moll gestimmt waren.

Eines war klar: Es musste wieder ein Chow-Chow sein, nur als Welpe hätte der Hund sein neues Domizil antreten können, und der Schreibende musste etwas an seinen Arbeitszeiten in der Praxis ändern. Dies war der wichtigste Schritt. Da wir eine geriatrische Praxis betreiben, war das Problem relativ rasch zu lösen. Patientenstammverkleinerung durch natürliche Fluktuation: Verstorbene Patienten und die, die einen Arztwechsel vorzunehmen gedachten, waren nicht zu ersetzen. Gleichsam ein befristeter Aufnahmestopp. Das hat funktioniert: Binnen eines Jahres hat sich der neue Modus vivendi zumindest teilweise eingespielt. In Spitzenzeiten der Beanspruchung funktioniert er noch immer nicht befriedigend, aber dazwischen schon.

Auf den Hund gekommen ist auch die Hundepolizei. Als wir unseren neuen Hund anmelden wollten, wurde uns expliziert, dass wir samt Hund während der Bürozeiten auf dem zuständigen Amt zu erscheinen hätten. Dafür hätten wir nötigenfalls, stünden wir in einem Angestellten-Verhältnis, vom Arbeitgeber einen halben Tag einfordern müssen, sei er als Ferien anzurechnen, sei er wegen Vollzugs einer Amtshandlung so zu gewähren.

Als Anregung für die Bürokraten wäre noch zu überlegen, ob man nicht analog zur Verkehrsmedizinischen Prüfung jeden Hundehalter periodisch darauf zu überprüfen hätte, ob er aus medizinischen Gründen allenfalls untauglich sei, einen Hund zu halten. Die Einnahme von stark sedierenden Medikamenten könnte ein solcher Hinderungsgrund sein, eine Checkliste wäre zu erstellen und danach zu handeln. Ein wahres Eldorado für die Legislatoren und Regulatoren, die doch in der heutigen Zeit Hochkonjunktur haben.

Möglicherweise komme ich bald noch mehr auf den Hund. Bereits erhalte ich von Krankenversicherern die ersten Schreiben, in denen sie den schrittweisen Abbau der Hausarztmodelle ohne Budgetmitverantwortung kommunizieren und dass man sich doch auf den bezeichneten Websites über bestehende Managed-Care-Organisationen (MCO) orientieren könne, mit dem Ziel, einer beizutreten. Ich würde vermutlich, sollte ich den Schritt zum Netzwerk nicht vollziehen, nur noch diejenigen Patienten weiterbetreuen, für die die finanzielle Mehrbelastung kein Problem darstellt und die davon überzeugt sind, dass sich für sie die Mehrkosten lohnen, weil sie um keinen Preis das wollen, was Managed Care auf Deutsch bedeutet: organisierte Fürsorge. So könnte ich vielleicht meine Arbeitszeit nochmals um die Hälfte reduzieren. Wahrscheinlich rechnet sich dann die Praxis jedoch nicht mehr und ich wäre gezwungen, vorzeitig in Pension zu gehen.

Solche Gedankenspiele sind unverbindlich. Für mich verbindlich ist hingegen meine Einschätzung, dass wir uns auch im noch freien Arztberuf immer mehr in Abhängigkeiten begeben, der Arztberuf kommt gleichsam auf den Hund.

Gibt es Auswege? Vielleicht schon, würden wir uns auf alte Werte besinnen:

«Hast Du das, was Du sagen willst, durch die drei Siebe gesiebt?», fragt Sokrates einen aufgeregten Redner. «Das der Wahrheit, das der Güte und das der Notwendigkeit. Durch diese drei Siebe soll alles, was wir sagen, gesiebt werden.» 